\title{
Modern and Ancient Out-of-Sequence Thrust in the Nankai Trough: Insight from Laboratory-Derived Properties and Seismic Data
}

\author{
by Takeshi Tsuji, Hidekazu Tokuyama, Gaku Kimura, and Shinya Okamoto
}

doi:10.2204/iodp.sd.s01.15.2007

\section{Introduction}

At convergent plate margins, characteristics of out-ofsequence thrusts (OOSTs) are important for understanding the nature of earthquake mechanisms and deformation of the accretionary prism. To understand the characteristics of OOSTs, Integrated Ocean Drilling Program (IODP) plans to drill through the seismogenic OOST in the Nankai Trough. In this phase, however, the seismogenic OOST is too deep to penetrate, so its properties have only been estimated from seismic data. Seismic reflection data from the Nankai Trough off the Kii Peninsula in southwest Japan (Figs. 1 and 2) image a strong negative polarity OOST (or splay fault) reflection branching from the major plate boundary fault (Park et al., 2002; Tsuru et al., 2005). This OOST might have ruptured during the 1944 Tonankai earthquake and associated tsunami (Tanioka and Satake, 2001). The negative polarity reflection of the OOST has been interpreted to indicate elevated fluid pressure in the fault zone (Park et al., 2002). From seismic data alone, the reflection polarity is highly useful information for estimating fault zone properties. However, polarity of deep seismic reflections is also affected by acoustic dispersion, and the fracture zone causes wavelet tuning (Costain and Coruh, 2004). Therefore, full characterization of OOST solely using reflection polarity is not possible. To investigate characteristics of a seismogenic OOST, we determined acoustic properties of discrete samples obtained from the fossil OOST outcrop in Nobeoka, and compared them with those of an active Kumano OOST imaged on seismic profile off the Kii peninsula. Because the Nobeoka OOST is interpreted as a fossil OOST, preserves in situ structure, and crops out (Kondo et al., 2005), it is ideal for evaluating characteristics of a seismogenic OOST.

\section{Results and Discussions}

$\mathrm{P}$-wave and S-wave velocities of discrete (minicore-shaped) samples were measured in dry conditions because in saturated conditions fluid dispersion masks pressure effects (Tsuji et al., 2006). We observed anisotropy of velocity in the hanging wall of the Nobeoka OOST attributed to foliation of politic phyllite (Fig. 3). Foliation-normal P-wave velocities in the hanging wall are $~ 700 \mathrm{~m} \mathrm{~s}^{-1}$ slower than the foliation-parallel velocities. In contrast, the footwall is composed of brittle, deformed, chaotic shales and fine sandstones, and velocities in the footwall are lower than those in the hanging wall. Furthermore, velocities increase just above the fault core (gray zones in Fig. 3), where velocity anisotropy at atmospheric pressure is weak and velocity increase with pressure is less apparent. These characteristics may be caused by the filling of most cracks with quartz, which is observed just above the fault core in the Nobeoka OOST. The shear-related dewatering and consolidation may also affect elastic moduli just above the fault core.

Comparison of the acoustic properties of the fossil Nobeoka OOST (determined from outcrop samples) and the active Kumano OOST (calculated from seismic reflection data) is warranted by the two thrusts'
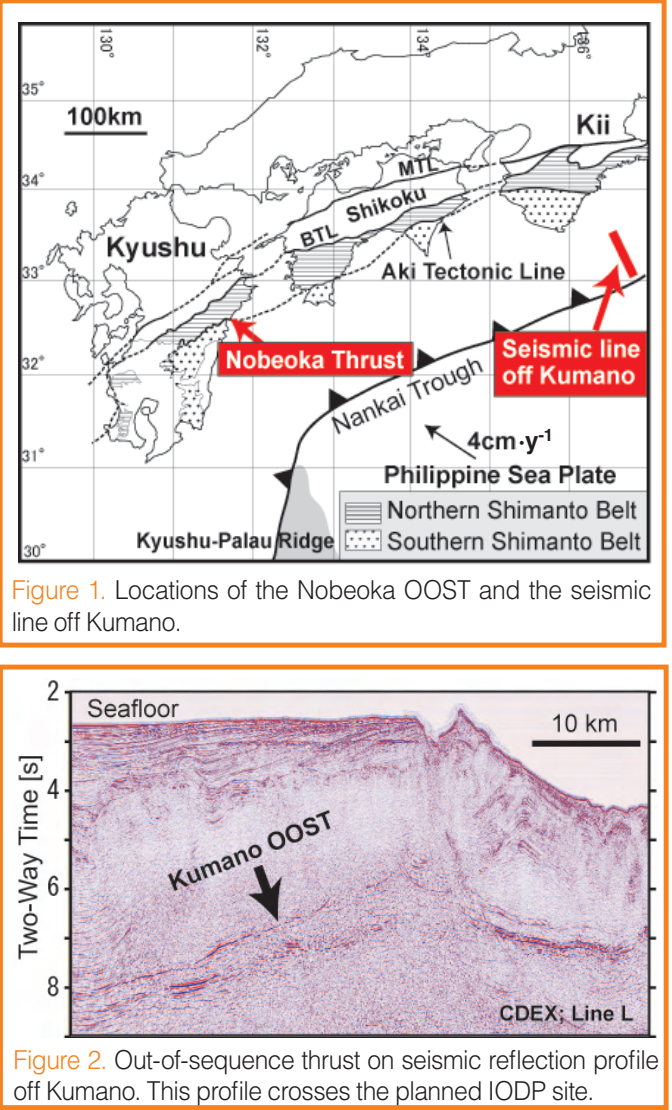
similar tectonic settings and lithologies. Weathering has affected properties of the Nobeoka OOST, but overall results from the hanging wall and the footwall should reflect trends of in situ properties. Furthermore, for the comparison of the fossil Nobeoka and active Kumano OOSTs, we calculated water-saturated $\mathrm{P}$-wave velocities from velocities determined under dry conditions via Gassmann's relation. If we assume an average bulk density of $2.5 \mathrm{~g} \mathrm{~cm}^{-3}$, a seafloor depth of $2 \mathrm{~km}$, an OOST depth of $7 \mathrm{~km}$, and hydrostatic conditions, effective pressure in the Kumano OOST is calculated to be $\sim 73 \mathrm{MPa}$. Assuming that velocities at $55 \mathrm{MPa}$ represent those at in situ effective pressures, the contrast between foliation-normal $\mathrm{P}$-wave velocities in hanging wall samples and footwall samples is $>600 \mathrm{~m} \mathrm{~s}^{-1}$. The change in P-wave velocities across the fault core of the Nobeoka OOST $\left(<600 \mathrm{~m} \mathrm{~s}^{-1}\right)$ is larger 
than that estimated from the reflection amplitude of the Kumano OOST (Tsuru et al., 2005). Therefore, Kumano OOST reflection amplitudes can be explained only by the difference in matrix elastic moduli of the Nobeoka OOST.

To compare Poisson's ratios of the Nobeoka and the active Kumano OOSTs, we modeled amplitude variation with offset (AVO) using the average $\mathrm{P}$-wave and S-wave velocities of Nobeoka samples at $55 \mathrm{MPa}$ and saturated conditions. The angle-dependent reflection coefficient (thick line in Fig. 4), obtained by the Zoeppritz equation compared to that of
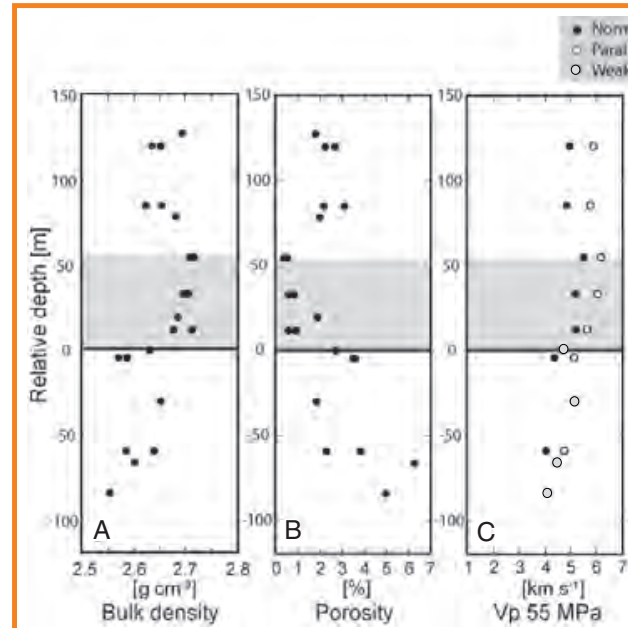

Nonmal to foliation (1) Porosity

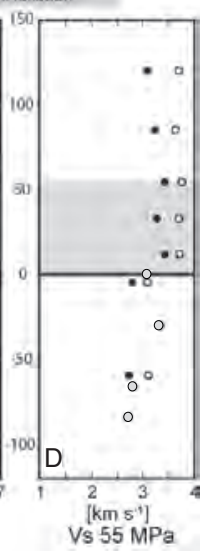

Figure 3. Depth profiles of $[\mathrm{A}]$ bulk densities, [B] porosities, [C] P-wave velocities at $55 \mathrm{MPa}$, and [D] S-wave velocities at $55 \mathrm{MPa}$ (Tsuji et al., 2006). Vertical axis represents depth relative to the location of fault core. Black solid dots, open dots, and gray dots represent acoustic properties normal to the foliation, parallel to the foliation, and weak foliation, respectively. Black lines and gray zones represent locations of the fault core and the high velocity interval, respectively.
Seismic Exploration, Volume 1, Amsterdam (Elsevier).

Dvorkin, J., Mavko, G., and Nur, A., 1999. Overpressure detection from compressional- and shear-wave data. Geophys. Res. Lett., 26:34173420, doi:10.1029/1999GL008382.

Kondo, H., Kimura, G., Masago, H., Ohmori-Ikehara, K., Kitamura, Y., Ikesawa, E., Sakaguchi, A. Yamaguchi, A., and Okamoto, S., 2005. Deformation and fluid flow of a major out-of-sequence thrust located at seismogenic depth in an accretionary complex: Nobeoka Thrust in the Shimanto Belt, Kyusyu, Japan. Tectonics, 24: TC6008, 10.1029/2004TC001655.

Park, J.-O., Tsuru, T., Kodaira, S., Cummins, P.R., and Kaneda, Y., 2002. Splay fault branching along the active Kumano OOST obtained by a two-ship, long-offset survey (dots in Fig. 4; Tsuru et al., 2005), shows a far offset reflection coefficient lower than that of the active Kumano OOST. If Poisson's ratios in the footwall are higher $(\sigma=\sim 0.25)$ than those of the Nobeoka OOST, the AVO response of the Nobeoka OOST coincides well with that of the active Kumano OOST. Because Poisson's ratio becomes higher with increasing pore fluid pressure (Dvorkin et al., 1999), high fluid pressure in the footwall likely explains the AVO response of the active Kumano OOST.

\section{Acknowledgements}

When we measured velocities of the outcrop discrete samples, F. Kono, T. Saeki, and H. Mochinaga (JOGMEC) provided devices to measure the velocities. Furthermore, we thank J. Ashi (ORI, Univ. Tokyo), G. Moore (CDEX, JAMSTEC), C. Moore (University of California, Santa Cruz), T. Tsuru (Cosmo Oil), and M. Coffin (ORI, University of Tokyo) for valuable discussions. Seismic reflection data (Fig. 2) are courtesy of CDEX, JAMSTEC.

\section{References}

Costain, J.K. and Çoruh, C., 2004. Basic theory of exploration seismology with Mathematica notebooks and examples on CDROM. Handbook of Geophysical Exploration,

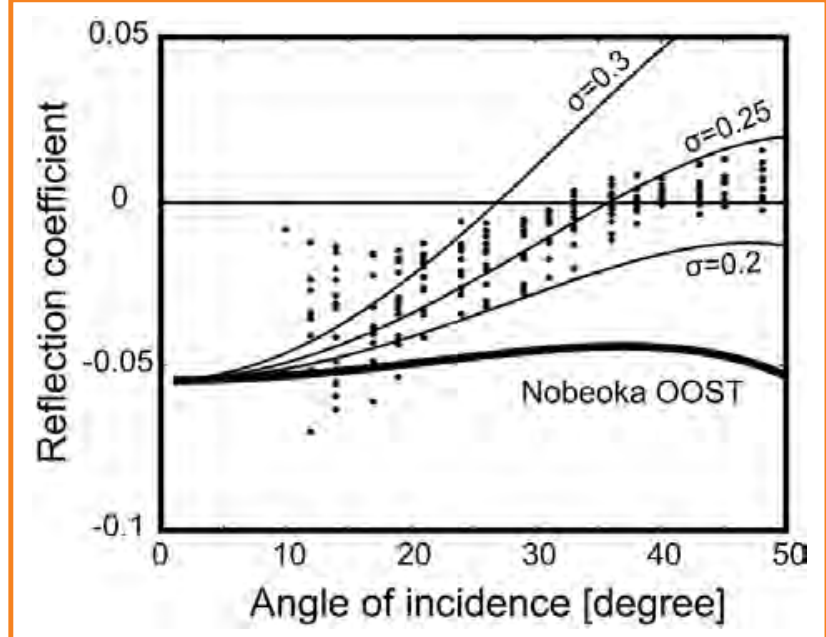

Figure 4. Comparison of angle-dependent reflection coefficients of discrete Nobeoka OOST samples (thick line) (Tsuji et al., 2006); the active Kumano OOST from seismic reflection data (solid dots) (Zone B in Tsuru et al., 2005). Thin lines represent reflection coefficients parameterized by Poisson's ratio. Poisson's ratios in the footwall of the Nobeoka OOST are lower than that of the active Kumano OOST, suggesting high fluid pressures in the footwall of the active Kumano OOST. the Nankai subduction zone. Science, 297:1157-1160, doi:10.1126/science.1074111.

Tanioka, Y. and Satake, K., 2001. Detailed coseismic slip distribution of the 1944 Tonankai earthquake estimated from tsunami waveforms. Geophys. Res. Lett., 28:1075-1078, doi:10.1029/ 2000GL012284.

Tsuji, T., Kimura, G., Okamoto, S., Kono, F., Mochinaga, H., Saeki, T., and Tokuyama, H., 2006. Modern and ancient seismogenic out-of-sequence thrusts in the Nankai accretionary prism: Comparison of laboratory-derived physical properties and seismic reflection data. Geophys. Res. Lett., 33:L18309, doi:10.1029 /2006GL027025.

Tsuru, T., Miura, S., Park, J.-O., Ito, A., Fujie, G., Kaneda, Y., No, T., Katayama, T., and Kasahara, J., 2005. Variation of physical properties beneath a fault observed by a two-ship seismic survey off southwest Japan. J. Geophys. Res., 110:B05405, doi: 10.1029/2004JB003036.

\section{Authors}

Takeshi Tsuji, Ocean Research Institute, The University of Tokyo, 1-15-1 Minamidai, Nakano-ku, Tokyo 164-8639, Japan, e-mail: tsuji@ori.u-tokyo. ac.jp.

Hidekazu Tokuyama, Ocean Research Institute, The University of Tokyo, 1-15-1 Minamidai, Nakano-ku, Tokyo 164-8639, Japan.

Gaku Kimura, Shinya Okamoto Department of Earth and Planetary Sciences, The University of Tokyo, Hongou 7-3-1, Bunkyo-ku, Tokyo, 113-0033, Japan. 